\title{
Behavioural adjustments of a large carnivore to access secondary prey in a human-dominated landscape
}

\author{
Valeix $\mathrm{M}^{1 *}$, Hemson $\mathrm{G}^{1 \#^{* *}}$, Loveridge $\mathrm{AJ}^{1}$, Mills $\mathrm{MGL}^{2}$ \& Macdonald DW
}

1 Wildlife Conservation Research Unit; Department of Zoology; University of Oxford; Recanati-Kaplan Centre; Tubney House; Abingdon Road; Oxfordshire OX13 5QL; United Kingdom

2 South African National Parks; Endangered Wildlife Trust; Mammal Research Institute; University of Pretoria; Private Bag X402; Skukuza 1350 South Africa

\# current address: Queensland Parks and Wildlife Service; 61 Yeppoon Road; Parkhurst; QLD 4702; Australia.

* both authors contributed equally to this work.

Correspondence: Graham Hemson; Queensland Parks and Wildlife Services; 61 Yeppoon Road; Parkhurst; QLD 4702; Australia (e-mail: graham.hemson@derm.qld.gov.au; phone:

+61 749360113; fax: +61 749360171)

Running title: Wild prey, livestock and lion ecology

Word count: 6956 (summary: 295 / main text: 4469 / acknowledgements: 132 / references:

1145 / tables: 630 / figure legends: 285)

Number of tables: 2

Number of figures: 5

Number of references: 43 


\section{Summary}

1. Conflict between people and large carnivores is an urgent conservation issue worldwide. Understanding the underlying ecological drivers of livestock depredation by large carnivores is greatly needed.

2. We studied the spatial, foraging and behavioural ecology of African lions Panthera leo in the Botswana Makgadikgadi ecosystem. This ecosystem comprises a protected area, characterized by high seasonal fluctuation in wild prey abundance, and adjacent lands, which are used for livestock grazing and characterized by stable livestock abundance, but also a risk of anthropogenic mortality.

3. Makgadikgadi lions preferentially preyed upon migratory wild herbivores when they were present, however, data from GPS radio-collared lions revealed that the majority of the study lions did not follow the migratory herds but remained resident at one or other border of the park and switched to livestock (abundant and readily available), and to a lesser extent resident wild herbivores (relatively scarce), in periods of migratory wild herbivore scarcity.

4. Resident lions' use of space differed between periods of wild prey abundance and scarcity. These changes were likely to increase the frequency of encounter with their primary prey in periods of primary prey abundance and with livestock in periods of primary prey scarcity.

5. The risk of conflict with humans was a major driver of lion ecology in the humandominated landscape surrounding the protected area. Resident lions generally avoided the close vicinity of cattle-posts. When they used such areas, they avoided temporal overlap with periods humans were most active and travelled at high speed reducing the time spent in these areas.

Synthesis and applications. This study suggests that lions balance the benefits of accessing livestock with the costs associated with livestock raiding. Hence, reduction in livestock 
availability through effective livestock husbandry in periods of wild prey scarcity should lead to reduced conflict.

Key-words: ecology of fear, human-wildlife conflict, lion, livestock, migration, stockraiding, wildebeest, zebra. 


\section{Introduction}

Conflict between people and large carnivores is an urgent conservation issue worldwide (Inskip \& Zimmermann 2009). Human-carnivore conflicts typically occur when wild carnivores prey on livestock, and the people affected respond by killing or harming carnivores. These conflicts appear to be increasing in frequency in many areas (Treves \& Karanth 2003), due to human population growth, presenting a significant threat to many carnivore species, including threatened ones (Macdonald, Loveridge \& Rabinowitz 2010), and to local peoples' livelihoods (Thirgood, Woodroffe \& Rabinowitz 2005). Research that advances understanding of predator-livestock interactions is important to conflict mitigation and carnivore conservation, yet most ecological research on carnivores has been conducted in areas without livestock (Graham, Beckerman \& Thirgood 2005). Hence, the spatial and foraging ecology of predators have rarely been studied in light of the relative abundance of wild prey and livestock.

Prey abundance and distribution are key drivers of carnivore ecology (see Macdonald \& Carr 1989; Loveridge et al. 2009 for home range configuration). Habitat selection by carnivores is largely driven by prey abundance (Palomares et al. 2001) and prey's vulnerability to predation (Hopcraft, Sinclair \& Packer 2005). It has been suggested that prey density influences carnivore search mode and movements (Valeix et al. 2010). While the role of prey in the spatial and behavioural ecology of carnivores is increasingly well understood in natural systems, little is known of the influence of the risk of conflict with humans on carnivore ecology. However, it is likely that carnivores moving in human-dominated landscapes adjust their behaviour not only to their prey but also to the risk of conflict with people.

Ecosystems where populations of large herbivores migrate seasonally provide unique opportunities to investigate how large carnivores adjust to seasonal variations in wild prey 
abundance. Few places in the world allow such studies, and even fewer where the proximity of livestock provides the opportunity to investigate the stock-raiding behaviour of carnivores in periods of wild prey scarcity. In this paper, we study the spatial, foraging and behavioural ecology of African lions Panthera leo in one of the last natural migratory systems, the Makgadikgadi Pans National Park in Botswana, where migratory movements of Burchell's zebra Equus quagga and blue wildebeest Connochaetes taurinus create contrasted periods of local wild prey abundance in different parts of the park on a seasonal basis (Loveridge et al. 2010). In addition to energetic costs, following migratory prey can induce large costs for territorial animals such as lions where the cost of losing an established territory and the consequent loss of reproductive potential and risk of infanticide may be higher than the cost of shifting to other less preferred prey (Packer, Scheel \& Pusey 1990; Heinsohn 1997; Mosser $\&$ Packer 2009). The protected area is surrounded by lands used for livestock grazing characterized by a stable abundance of livestock year-round. Hence, livestock are likely to represent important secondary prey in this ecosystem. There are many concerns about livestock depredation by lions in these adjacent lands and the number of lions lost to humancarnivore conflicts is significant (Hemson et al. 2009).

This study focused mainly on the ecology of lions that remained resident throughout the year close to the boundary of the park ('resident lions' hereafter), and not on lions that followed migratory movements of wild prey. We first assessed prey preference of resident lions in periods of wild prey abundance and wild prey scarcity. We then investigated whether they shift their space use from areas inside the park in periods of wild prey abundance to areas outside the park and closer to cattle-posts (human settlements with livestock herding practice) in periods of wild prey scarcity as a result of a shift in diet. We also assessed whether resident lions have larger home ranges when wild prey are scarce because of the lower prey encounter rate. Finally, we expected lions to show seasonal differences in their movements inside the 
national park, with higher speed and longer distances covered in periods of wild prey scarcity to compensate for the low encounter rate, but no seasonal difference when outside the park due to the stable abundance of livestock throughout the year.

The study system also provides a good opportunity to assess whether lions perceive a risk of conflict with people and associated anthropogenic mortality and adjust their behaviour accordingly when they move into increasingly human-dominated landscapes. The 'ecology of fear' theory (Brown, Laundré \& Gurung 1999) and the 'landscape of fear' concept (Laundré, Hernández \& Altendorf 2001) have been used extensively in the literature to explain aspects of prey behavioural ecology, but have not previously been applied to carnivore behavioural ecology. Because of the risk of retaliatory killing by humans, areas in the close vicinity of a cattle-post are dangerous for lions. We predicted that (i) lions should avoid areas in the close vicinity of cattle-posts, reducing spatial overlap with people, (ii) lions should become more nocturnal in these areas, reducing temporal overlap with human activity, and (iii) lions should move at high speed in these areas, reducing the time spent in these high risk areas.

\section{Materials and methods}

\section{STUDY SITE}

The study area comprised the $4900 \mathrm{~km}^{2}$ Makgadikgadi Pans National Park, which lies between latitude $20^{\circ}$ and $21^{\circ}$ and longitude $20^{\circ}$ and $26^{\circ}$ in Central Botswana and adjacent lands used for livestock grazing (ca. $3000 \mathrm{~km}^{2}$ ). The park is surrounded on approximately $75 \%$ of its boundary by wildlife management areas predominantly used for livestock-rearing by local people ( 4 villages and over 150 cattle-posts). The park is bordered to the North by the Nxai Pan National Park, to the West by the seasonally dry Boteti River, with a few perennial 
waterholes, and to the South-East by Ntwetwe salt pan. The salt pan is inhospitable for most animals. The vegetation consists of grasslands associated with seasonal pans, grasslands on well-drained saline sands, and tree savanna dominated by Acacia spp., Lonchocarpus spp., Boschia spp., and Terminalia spp. Riverine vegetation occurs along the Boteti River. Over $80 \%$ of rainfall (250-450mm per annum) falls between October and April, but inter-annual spatial and temporal variation is considerable (Thomas \& Shaw 1991). In this study, we defined the 3-month period June-July-August as the core of the dry season (dry season hereafter) and the 3-month period December-January-February as the core of the wet season (wet season hereafter). At the time of the study (2001-2003), lion density was estimated around $0.5-0.7$ lions $/ 100 \mathrm{~km}^{2}$ in the study area (Hemson 2003).

\section{PREY INFORMATION}

The area supports a migratory population of zebra and wildebeest. These two species move en masse (estimated number of animals $\sim 19000$ ) from West to East in the wet season, returning to the West in the dry season as the availability of drinkable surface water and fresh grazing declines in the East (Loveridge et al. 2010). We defined the periods during which migratory herbivores were present as 'migratory prey periods' (equivalent to the dry season in the West and the wet season in the East) and the periods during which migratory herbivores were absent as 'resident prey periods' (equivalent to the wet season in the West and to the dry season in the East). Conversely, livestock (cow, donkey, goat, horse) abundance is high and stable throughout the year $(\sim 11500$ animals in the West and $\sim 17800$ in the East; Loveridge et al. 2010). There are some resident populations of wild prey (greater kudu Tragelaphus strepsiceros, gemsbok Oryx gazella, hartebeest Alcelaphus buselaphus) but present at lower abundance (between 3500 and 4800 resident wild animals in the West and between 1400 and 2400 in the East). Livestock in the study area are usually released from protective enclosures 
in the morning and left to graze unattended during the day. Cattle herders do not fetch in stock at night but wait for it to return to the cattle-post for water; as a consequence, livestock movements are fairly predictable and $13 \%$ of livestock are left out at night (Hemson et al. 2009). Ninety five percent of cattle locations recorded with GPS collars are within $6 \mathrm{~km}$ of cattle-posts in which they overnight (Hemson 2003). This radius represents the area where lions are likely to encounter livestock.

\section{LION DATA}

Lions were monitored with GPS collars in the study area between 2001 and 2003. Nine lions (3 males and 6 females) were fitted with GPS radio-collars (Televilt Simplex 2-D). These 9 individuals belong to 9 different groups. For each animal, one location was available hourly from 18:00 to 6:00 and then at 9:00 and 16:00. A previous study showed that migratory wild herbivores represent $78 \%$ of resident lion kills in the migratory prey periods, whereas when they are absent, livestock represent $85 \%$ of lion kills (Loveridge et al. 2010). We used these published data to estimate prey preference using the Jacob's index (Jacobs 1974). Jacobs' index, $\mathrm{D}=(r-p) /(r+p-2 r p)$, standardizes the relationship between the relative proportion that each prey category makes up of lion kills $r$ and prey relative abundance $p$. The standardized values range from +1 to -1 , where +1 indicates maximum preference and -1 maximum avoidance. Because most of the prey species in the study area are large species of similar body size, we assumed that all prey were equally detectable in the lion's diet and we did not correct the index for the size of the prey.

\section{HOME RANGE ANALYSES}

Lion home ranges were calculated using the local convex hull ( $\mathrm{LoCoH})$ non parametric kernel method (Getz \& Wilmers 2004; Getz et al. 2007) with heuristic value $k=\sqrt{ } \mathrm{n}$ ( $\mathrm{n}$ is the number 
of points in the set). For each individual, we calculated the animal's global home range based on all locations available (used for the habitat selection analyses) and monthly home ranges. Only monthly home ranges for which ca. 400 locations were available (a minimum of 13 locations every day) were estimated. Home range analyses were undertaken using the extension LoCoH v.2.1. for ArcView (version 3.2, Environmental Systems Research Institute Inc., Redlands, USA). We first calculated the proportion of each monthly home range in the West area of the ecosystem to evaluate the proportion of study lions that shifted their home range to follow the migration. We then calculated the size of each monthly home range and performed linear mixed model analyses with lion identity included as a random factor and period of prey abundance as a fixed factor to test the hypothesis that monthly home ranges were larger during resident prey periods. Linear mixed models were performed with SAS software (version 8.2), using MIXED procedure and restricted maximum likelihood estimation method.

\section{HABITAT SELECTION ANALYSES}

We performed compositional analyses (Aebischer, Robertson \& Kenward 1993), a method that uses individuals as sampling units, using the package "adehabitat" for R software (Calenge 2006) to test the hypothesis that resident lions preferentially used areas located inside the national park in the migratory prey periods whereas they preferentially used areas close to cattle-posts in the resident prey periods. Distance to cattle-posts was categorized into seven classes: $0-1 \mathrm{~km}, 1-2 \mathrm{~km}, 2-3 \mathrm{~km}, 3-4 \mathrm{~km}, 4-5 \mathrm{~km}, 5-6 \mathrm{~km}$ and $>6 \mathrm{~km}$ (this last class corresponds to areas from which cattle were largely absent). For each animal and for each period of prey abundance, we calculated the proportion of locations within each distance-tocattle-post class (representative of site use) and the proportion of each distance-to-cattle-post class in the animal's global home range (representative of site availability). Site preferences 
were represented by the Jacob's index . Here, $r$ represents the relative proportion that each habitat type makes up of an animal locations and $p$ habitat relative abundance (i.e. the proportion that each habitat type makes up the animal home range). A Jacobs' index value was calculated for each individual and each period of prey abundance, and we then calculated a mean Jacobs' index for each of the distance-to-cattle-post class.

\section{LION BEHAVIOURAL ADJUSTMENTS CLOSE TO CATTLE-POSTS}

We first assessed whether lions avoided the use of areas close to cattle-posts during the day, i.e. when humans are known to be active, by testing for each class of distance to a cattle-post whether the locations were distributed in equal proportions amongst the different hours of the day or whether there was a temporal segregation of lion and human activity. We then investigated whether lions moved faster when close to human settlements, i.e. cattle-posts. We used Hawth's tools for ESRI ArcMap 9.2 (Beyer 2007) to extract travel speed for each hour of the night. We performed a covariance analysis on these speeds with lion identity and night identity as random effects. As temporal serial autocorrelation may affect the data from a same night, we checked whether autocorrelation was present and accounted for it using a firstorder autoregressive covariance structure. For locations inside the park and further than $6 \mathrm{~km}$ from a cattle-post, we tested the effect of period only, whereas for locations within $6 \mathrm{~km}$ of a cattle-post, we tested the effect of period, distance-to-cattle-post, and the interaction between these two variables. 


\section{Results}

\section{HOME RANGES}

Only 2 females out of the 9 collared individuals appeared to shift their home range to follow the migratory movements of wild prey (see example Fig 1a). The other 7 individuals were residents, either in the West area (4 individuals; see example Fig. 1b) or in the East area (3 individuals; see example Fig. 1b). As expected, the size of monthly home ranges did not differ between periods for lions that followed the herbivore migration $\left(\mathrm{F}_{1,14}=0.04 ; P=0.84\right)$. Their mean monthly home range size was $256 \mathrm{~km}^{2}\left(\mathrm{SE}=35 \mathrm{~km}^{2}\right.$; range $\left.=93-625 \mathrm{~km}^{2}\right)$. The size of monthly home ranges was not influenced by the period of prey abundance for resident lions neither $\left(\mathrm{F}_{1,51}=0.28 ; P=0.60\right)$. Resident male monthly home ranges were significantly larger than those of resident females $\left(\mathrm{F}_{1,52}=100.19 ; P<0.0001\right)$. Mean monthly home range size was $531 \mathrm{~km}^{2}\left(\mathrm{SE}=41 \mathrm{~km}^{2} ;\right.$ range $\left.=152-1006 \mathrm{~km}^{2}\right)$ and $88 \mathrm{~km}^{2}\left(\mathrm{SE}=16 \mathrm{~km}^{2}\right.$; range $=6-448$ $\mathrm{km}^{2}$ ) for resident males and females respectively. Resident females had smaller monthly home ranges than did females that followed the migration $\left(\mathrm{F}_{1,45}=8.56 ; P=0.0054\right)$. Hereafter, we focused on the study of how resident lions adjusted their ecology to seasonal variations in wild prey abundance.

\section{FORAGING BEHAVIOUR}

Migratory wild prey (zebra and wildebeest) were largely preferred when they were present (Fig. 2). No significant preference could be detected between resident prey in the resident prey periods, even though livestock tended to be selected slightly more than resident wild prey (Fig. 2). Data from the kill sites studied in Loveridge et al. (2010) revealed that on average, lions killed livestock at $4.5 \mathrm{~km}$ from a cattle-post $(\mathrm{SE}=1.0 \mathrm{~km})$. Lions killed migratory wild prey significantly further from cattle-posts in migratory prey periods (estimate 
$\pm \mathrm{SE}=14.4 \pm 2.3 \mathrm{~km})$ than in resident prey periods (estimate $\pm \mathrm{SE}=6.8 \pm 1.9 \mathrm{~km})\left(\mathrm{F}_{1,51}=\right.$ $10.97 ; P=0.0017)$.

\section{HABITAT SELECTION}

Lions of both sexes showed significant spatial selection patterns in both regimes of wild prey abundance (female migratory prey period $\lambda=0.339 ; P=0.038$; female resident prey period: $\lambda=0.225 ; P=$ 0.002; male migratory prey period: $\lambda=0.012 ; P=0.002$; male $\left._{\text {resident prey period }}: \lambda=0.045 ; P=0.004\right)$, but spatial selection patterns differed between periods. In migratory prey periods, lions of both sexes avoided areas located within $3 \mathrm{~km}$ of a cattle-post (Table 1a and c; Fig. 3). Whereas females used all other areas in proportion to their availability (Fig. 3a), males preferentially used areas located between 4 and $6 \mathrm{~km}$ from a cattle-post and avoided use of areas further away (Fig. 3b). In resident prey periods, lions of both sexes significantly avoided areas further than $6 \mathrm{~km}$ from a cattle-post (Table $1 \mathrm{~b}$ and d; Fig. 3). Even in these periods, areas within $1 \mathrm{~km}$ of a cattle-post were avoided (Table $1 \mathrm{~b}$ and d; Fig. 3).

\section{LION BEHAVIOURAL ADJUSTMENTS CLOSE TO CATTLE-POSTS}

Lion locations were not distributed equally amongst the different hours in the $0-1 \mathrm{~km}$ class of

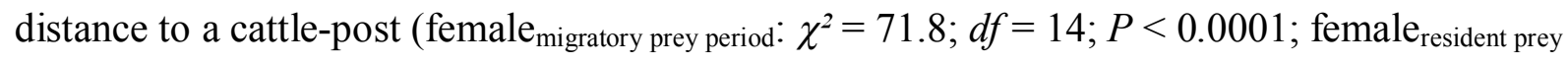
period: $\chi^{2}=180.9 ; d f=14 ; P<0.0001 ;$ male $_{\text {migratory prey period }}: \chi^{2}=41.6 ; d f=14 ; P=0.0001$; male $_{\text {resident prey period }}: \chi^{2}=130.3 ; d f=14 ; P<0.0001$ ), in the $1-2 \mathrm{~km}$ class (female migratory prey period: $\chi^{2}=67.0 ; d f=14 ; P<0.0001 ;$ female $_{\text {resident prey period }}: \chi^{2}=93.4 ; d f=14 ; P<0.0001 ;$ male $_{\text {migratory prey period: }} \chi^{2}=61.9 ; d f=14 ; P<0.0001 ;$ male $_{\text {resident prey period }}: \chi^{2}=90.2 ; d f=14 ; P<$ $0.0001)$, and in the $2-3 \mathrm{~km}$ class for males in the migratory prey period only $\left(\chi^{2}=48.1 ; d f=\right.$ $14 ; P<0.0001)$. There was a clear avoidance of use of areas close to cattle-posts between 0600h and 2000h (Fig. 4), coinciding with the period of human activity. This temporal 
avoidance did not exist in other classes of distance to cattle-posts where locations were distributed in equal proportion amongst the different hours $(P \geq 0.05$; not shown).

The relationships reported in Fig. 5a and d between average speed of lions and distance to a cattle-post for resident females and males revealed a clear break-point at a distance of approximately $6 \mathrm{~km}$ from a cattle-post. The points further than $6 \mathrm{~km}$ generally corresponded to locations in the national park (Fig. $5 \mathrm{~b}$ and e). Within $6 \mathrm{~km}$ of a cattle-post, females moved significantly faster as they approached a cattle-post (slope estimate $\pm \mathrm{SE}=-$ $0.09 \pm 0.01$; Fig. $5 \mathrm{a}$; see table 2 for statistics). Within $6 \mathrm{~km}$ of a cattle-post, the relationship between speed and distance from a cattle-post was also negative for males but not significant

(Fig. 5d). As expected, there was no seasonal effect on both female and male speed between 0 and $6 \mathrm{~km}$ from a cattle-post whereas there was a seasonal effect for both sexes inside the national park (Fig. 5c and f; Table 2). Both sexes moved faster during the resident prey periods (estimate mean speed $\pm \mathrm{SE}=499 \pm 62 \mathrm{~m} / \mathrm{h}$ for females and $1349 \pm 51 \mathrm{~m} / \mathrm{h}$ for males) than during the migratory prey periods (estimate mean speed $\pm \mathrm{SE}=436 \pm 26 \mathrm{~m} / \mathrm{h}$ for females and $1209 \pm 138 \mathrm{~m} / \mathrm{h}$ for males) (Fig. $5 \mathrm{c}$ and $\mathrm{f}$ ).

\section{Discussion}

This study shows that in a system characterized by wide seasonal fluctuation in wild prey abundance, some lions adopted a resident strategy and periodically raided livestock when wild prey were scarce. Livestock are relatively easy to capture and are predictably distributed in space and time. Resident lions mainly killed stray livestock and showed behavioural adjustments likely to reduce the probability of encounters with humans, and hence of anthropogenic mortality. This study suggests that lions balanced the benefits of accessing livestock with the costs associated with livestock raiding. 


\section{LIVESTOCK: IMPORTANT SECONDARY PREY IN THE RESIDENT PREY PERIODS}

Makgadikgadi lions had a noticeable preference for migratory herbivores when these were available, however, the majority of the collared lions did not follow the migratory herds. This supports other research on lion territoriality in systems with migratory prey (Mosser \& Packer 2009). In the Serengeti National Park, Tanzania, lions preferentially prey upon migratory species when migratory prey are present, with only a small nomadic segment of the population following the migratory herds (Schaller 1972; Hanby, Bygott \& Packer 1995). Most lions are resident and territorial (Mosser \& Packer 2009) and rely on resident prey in the absence of migratory prey (Scheel \& Packer 1995). These findings confirm that the costs associated with following migratory prey (both energetic costs and the significant costs of losing an established territory, and associated reproductive loss and risk of infanticide) are likely to be higher than the cost of shifting to other less preferred prey.

In our study, a stable but low abundance of wild resident prey species and a predictably high abundance of livestock allowed most lions to remain resident during the resident prey periods. Prey preference data suggested that lions killed resident wild prey and livestock in proportion to their availability when migratory prey were absent, with a slight preference for livestock (see also Meriggi \& Lovari 1996 for wolves). Livestock represent a large proportion of lion diet in the resident prey periods ( $85 \%)$ because of their high abundance. Changes in use of space by resident lions are associated with this change in diet. These changes are likely to increase the frequency of encounter with primary prey in periods of primary prey abundance (avoidance of areas within $3 \mathrm{~km}$ of cattle-posts) and with secondary prey in periods of primary prey scarcity (avoidance of areas further than $6 \mathrm{~km}$ of cattle-posts). While it is risky to raid, livestock are predictably distributed around permanent loci (cattle-posts) and in abundance throughout the year. Resident lions are likely to benefit 
from the predictable distribution of these secondary prey by using smaller, permanent home ranges. Resident females had stable monthly home ranges three times smaller than those of females that followed the migration of wild herbivores.

Overall, these findings suggest that the balance of the cost-benefit trade-off of raiding livestock changes with the availability of wild prey. They support the hypothesis that availability of wild prey affects the potential for conflict and depredation rates tend to be higher in areas where, or at a time of year when, wild prey are less abundant (Sillero-Zubiri \& Laurenson 2001; but see Stahl et al. 2002 for opposite findings).

\section{A LANDSCAPE OF FEAR FOR LIONS}

In the areas adjacent to the Makgadikgadi Pans National Park, pastoralists openly expressed a willingness to kill lions in retaliation for livestock predation (Hemson et al. 2009) and at least 8 adult lions were killed by herders during the study. Our results revealed a range of behavioural adjustments made by resident lions likely to reduce the risk of encountering people, and hence of anthropogenic mortality. Lions, and females in particular, avoided the close vicinity of cattle-posts $(<1 \mathrm{~km})$ in the resident prey periods in spite of their spatial adjustments to access and dietary shift towards use of livestock. On average, they ambushed livestock between 4 and $5 \mathrm{~km}$ from a cattle-post, i.e. in areas where livestock were left unattended during the day and sometimes at night. Avoidance of risky environments has already been reported for predator-prey relationships (Ripple \& Beschta 2004; Creel et al. 2005; Valeix et al. 2009a), as well as at the intra-guild level (Voigt \& Earle 1983). When lions used areas close to cattle-posts, they avoided temporal overlap with periods humans were most active and travelled at high speed, hence reducing the time spent in these areas. Temporal adjustments to avoid dangerous periods have already been documented for prey avoiding periods coinciding with predator hunting (Roth \& Lima 2007; Valeix et al. 2009b), 
as well as at the intra-guild level to avoid potential aggressions (Harrington et al. 2009). The results uphold our predictions and add support to the 'landscape of fear' hypothesis as it applies to the Makgadikgadi lions. The 'ecology of fear' has been developed for predator-prey relationships and to a lesser extent applied at the carnivore intra-guild level, and our study supports that it can be applied to carnivores moving in human-dominated landscapes (see also Theuerkauf et al. 2003 for wolves; Berger 2007 for use of human infrastructure as a shield against carnivores by prey).

The relationship between average travel speed and distance to cattle-posts, particularly for females, strongly suggests that whereas prey abundance is likely to be the main driver of lion ecology inside the protected area, the risk of conflict with humans is a major driver in the human-dominated landscape surrounding the protected area. Alternative hypotheses to explain the avoidance of the immediate vicinity of cattle-posts by lions and the high speed of lions when they use such areas could be advanced (e.g. very low abundance of wild prey in these areas, change in vegetation structure). However, our knowledge of the area does not provide much weight to these alternative hypotheses and the wide range of behavioural adjustments made by lions in the vicinity of cattle-posts uphold the hypothesis of the ecology of fear. We believe our study brings new insight by suggesting that the costs of conflicts with humans for carnivores, which have been traditionally measured by and reported as the direct impact of retaliatory killing or harming of carnivores by humans, may also include some indirect costs associated with the behavioural adjustments made by carnivores to minimize encounters with humans. Overall, our results call for further investigation of the ecology of fear as applied to carnivores. 
TO RAID OR NOT TO RAID, IMPLICATIONS FOR THE MITIGATION OF HUMAN-

\section{CARNIVORE CONFLICTS}

Our study lends support to the idea that wild prey availability and reduction in livestock availability through effective livestock husbandry are important variables in controlling livestock predation (Woodroffe, Thirgood \& Rabinowitz 2005). In this study the majority of livestock killed by lions were stray livestock killed on average between 4 and $5 \mathrm{~km}$ from a cattle-post. This pattern contrasts with that observed elsewhere, where lions enter livestock enclosures to kill livestock (Ogada et al. 2003). It suggests that effective use of protective enclosures may play an important role in reducing livestock vulnerability in the Makgadikgadi ecosystem. The availability of unattended livestock away from cattle-posts was a major driver of livestock predation in the study area. Reducing the abundance of livestock left unattended at night would significantly reduce livestock predation in the Makgadikgadi and similar areas. In the study area, livestock depredation is highly seasonal with a peak of depredation occurring in the wet season in the West of the system and in the dry season in the East. It appears that improved herding and husbandry practices could be targeted towards the critical seasons where livestock losses are greatest.

Improved livestock husbandry (particularly more consistent use of protective enclosures and improved supervision of grazing stock) would act to limit the current levels of livestock depredation by lions. Such measures could be implemented in periods when livestock are most vulnerable only. However, it is not clear that such interventions are in fact realistic or likely to be implemented in the current socio-economic landscape. Hemson et al. (2009) show that local people, particularly cattle owners are generally hostile towards lions and benefit little from local tourism, community based conservation or living in the proximity to the park. Responsibility for livestock depredation is perceived to be held by the government. While State funded compensation for livestock losses is available in Botswana, 
this does not cover the costs of replacement and is often difficult and time consuming for livestock owners to access. Improving husbandry practices to minimize livestock predation is a first crucial step, but putting in place an adequate incentive structure (including benefit sharing, financial incentives and adequate compensation; Dickman, Macdonald \& Macdonald in press) that promotes tolerance of lions and other wildlife may ultimately have the most impact and provide the most benefit to carnivore conservation.

\section{Acknowledgements}

This study was completed with the generous assistance and permission of the Botswana government and the support of the Rufford Foundation, the Peoples Trust for Endangered Species, the Wildlife Café, D. Atkinson, Born Free, the Okavango Wildlife Society, K. Taylor and Watkins Incorporated. M.G. L. M. was supported by the Tony and Lisette Lewis Foundation. The manuscript has benefited enormously from comments and feedback from J. Kamler, P. Johnson, L. Frank, H. Fritz, S. Chamaillé-Jammes, G. Hopcraft and one anonymous reviewer. The data collection undertaken with considerable assistance from S. Maclennan, T. Mathemba, G. Bino, I. Moremi, S. Wetten, K. Molepo and V. Cole. Special thanks to the staff of Uncharted Africa and Leroo la Tau. Analyses and preparation of this paper were supported by a grant from Tom and Daphne Kaplan.

\section{References}

Aebischer, N.J., Robertson, P.A. \& Kenward, R.E. (1993) Compositional analysis of habitat use from animal radio-tracking data. Ecology, 74, 1313-1325. 
Berger, J. (2007) Fear, human shields and the redistribution of prey and predators in protected areas. Biology letters, 3, 620-623.

Beyer, H.L. (2007) Hawth's analysis tools for ArcGIS, version 3.27. Available from http://www.spatialecology.com/htools

Brown, J.S., Laundré, J.W. \& Gurung, M. (1999) The ecology of fear: optimal foraging, game theory, and trophic interactions. Journal of Mammalogy, 80, 385-399.

Calenge, C. (2006) The package "adehabitat" for the R software: a tool for the analysis of space and habitat use by animals. Ecological Modelling, 197, 516-519.

Creel, S., Winnie, J.A., Maxwell, B., Hamlin, K. \& Creel, M. (2005) Elk alter habitat selection as an antipredator response to wolves. Ecology, 86, 3387-3397.

Dickman, A.J., Macdonald, E.A. \& Macdonald D.W. (in press) A review of financial instruments to pay for predator conservation and encourage human-carnivore coexistence. Proceedings of the National Academy of Sciences (doi: 10.1073/pnas.1012972108).

Getz, W.M. \& Wilmers, C.C. (2004) A local nearest-neighbor convex-hull construction of home ranges and utilization distributions. Ecography, 27, 489-505.

Getz, W.M., Fortmann-Roe, S., Cross, P.C., Lyons, A.J., Ryan, S.J. \& Wilmers, C.C. (2007) LoCoH: nonparametric kernel methods for constructing home ranges and utilization distributions. PlosOne, 2, e207. 
Graham, K., Beckerman, A. P. \& Thirgood, S. (2005) Human-predator-prey conflicts: ecological correlates, prey losses and patterns of management. Biological Conservation, 122, $159-171$

Hanby, J.P., Bygott, J.D. \& Packer, C. (1995) Ecology, demography, and behavior of lions in two contrasting habitats: Ngorongoro Crater and the Serengeti Plains. Serengeti II: Dynamics, Management, and Conservation of an Ecosystem (eds A.R.E. Sinclair \& P. Arcese), pp. 315331. The University of Chicago Press, Chicago.

Harrington, L.A., Harrington, A.L., Yamaguchi, N., Thom, M.D., Ferreras, P., Windham, T.R. \& Macdonald, D.W. (2009) The impact of native competitors on an alien invasive: temporal niche shifts to avoid interspecific aggression. Ecology, 90, 1207-1216.

Heinsohn, R. (1997) Group territoriality in two populations of African lions. Animal Behaviour, 53, 1143-1147.

Hemson, G. (2003) The ecology and conservation of lions: human-wildlife conflict in semiarid Botswana. $\mathrm{PhD}$ thesis, University of Oxford.

Hemson, G., Maclennan, S., Mills, G., Johnson, P. \& Macdonald, D.W. (2009) Community, lions, livestock and money: a spatial and social analysis of attitudes to wildlife and the conservation value of tourism in a human-carnivore conflict in Botswana. Biological Conservation, 142, 2718-2725. 
Hopcraft, J.G., Sinclair, A.R.E. \& Packer, C. (2005) Planning for success: Serengeti lions seek prey accessibility rather than abundance. Journal of Animal Ecology, 74, 559-566.

Inskip, C. \& Zimmermann, A. (2009) Human-felid conflict: a review of patterns and priorities worldwide. Oryx, 43, 18-34.

Jacobs, J. (1974) Quantitative measurement of food selection - a modification of the forage ratio and Ivlev's electivity index. Oecologia, 14, 413-417.

Laundré, J.W., Hernández, L. \& Altendorf, K.B. (2001) Wolves, elk, and bison: reestablishing the "landscape of fear" in Yellowstone National Park, USA. Canadian Journal of Ecology, 79, 1401-1409.

Loveridge, A.J., Valeix, M., Davidson, Z., Murindagomo, F., Fritz, H. \& Macdonald, D.W. (2009) Changes in home range size of African lions in relation to pride size and prey biomass in a semi-arid savanna. Ecography, 32, 953-962.

Loveridge, A.J., Hemson, G., Davidson, Z. \& Macdonald, D.W. (2010) African lions on the edge: reserve boundaries as 'attractive sinks'. Biology and Conservation of Wild Felids (eds D.W. Macdonald \& A.J. Loveridge), pp. 283-304. Oxford University press, Oxford.

Macdonald, D.W. \& Carr, G.M. (1989) Food security and the rewards of tolerance.

Comparative socioecology: the behavioural ecology of humans and other mammals (eds V. Standen \& R.A. Folley), pp. 75-99. Blackwell Scientific Publications, Oxford. 
Macdonald, D.W., Loveridge, A.J. \& Rabinowitz, A. (2010) Felid futures: crossing disciplines, borders, and generations. Biology and Conservation of Wild Felids (eds D.W. Macdonald \& A.J. Loveridge), pp. 599-649. Oxford University press, Oxford.

Meriggi, A. \& Lovari, S. (1996) A review of wolf predation in Southern Europe: does the wolf prefer wild prey to livestock? Journal of Applied Ecology, 33, 1561-1571.

Mosser, A. \& Packer, C. (2009) Group territoriality and the benefits of sociality in the African lion, Panthera leo. Animal Behaviour, 78, 359-370.

Ogada, M., Woodroffe, R., Oguge, N. \& Franck, L. (2003) Limiting depredation by African carnivores: the role of animal husbandry. Conservation Biology, 17, 1521-1530.

Packer, C., Scheel, D. \& Pusez, A.E. (1990) Why lions form groups: food is not enough. The American Naturalist, 136, 1-19.

Palomares, F., Delibes, M., Revilla, E., Calzada, J. \& Fedriani, J.M. (2001) Spatial ecology of Iberian lynx and abundance of European rabbits in south-western Spain. Ecological Monographs, 148, 1-36.

Ripple, W.J. \& Beschta, R.L. (2004) Wolves and the ecology of fear: can predation risk structure ecosystems? BioScience, 54, 755-766.

Roth, T.C. \& Lima, S.L. (2007) The predatory behavior of wintering Accipiter hawks: temporal patterns in activity of predators and prey. Oecologia, 152, 169-178. 
Schaller, G.B. (1972) The Serengeti lion. University of Chicago Press, Chicago.

Scheel, D. \& Packer, C. (1995) Variation in predation by lions: tracking a movable feast. Serengeti II: Dynamics, Management, and Conservation of an Ecosystem (eds A.R.E. Sinclair \& P. Arcese), pp. 299-314. University of Chicago Press, Chicago.

Sillero-Zubiri, C. \& Laurenson, M.K. (2001) Interactions between carnivores and local communities: conflict or co-existence? Carnivore Conservation (eds J.L. Gittleman, S.M. Funk, D.W. Macdonald \& R.K. Wayne), pp. 282-312. Cambridge University Press, Cambridge.

Stahl, P., Vandel, J.M., Ruette, S., Coat, L., Coat, Y. \& Balestra, L. (2002) Factors affecting lynx predation on sheep in the French Jura. Journal of Applied Ecology, 39, 204-216.

Theuerkauf, J., Jedrzejewski, W., Schmidt, K. \& Gula, R. (2003) Spatiotemporal segregation of wolves from humans in the Bialowieza Forest (Poland). The Journal of Wildlife Management, 67, 706-716.

Thirgood, S., Woodroffe, R. \& Rabinowitz, A. (2005) The impact of human-wildlife conflict on human lives and livelihoods. People and Wildlife, Conflict or Coexistence? (eds R. Woodroffe, S. Thirgood \& A. Rabinowitz), pp. 13-26. Cambridge University Press, Cambridge. 
Thomas, D.S.G. \& Shaw, P.A. (1991) The Kalahari environment. Cambridge University Press, Cambridge.

Treves, A. \& Karanth, K. U. (2003) Human-carnivore conflict and perspectives on carnivore management worldwide. Conservation Biology, 17, 1491-1499.

Valeix, M., Loveridge, A.J., Chamaillé-Jammes, S., Davidson, Z., Murindagomo, F., Fritz, H. \& Macdonald, D.W. (2009a) Behavioral adjustments of African herbivores to predation risk by lions: spatiotemporal variations influence habitat use. Ecology, 90, 23-30.

Valeix, M., Fritz, H., Loveridge, A.J., Davidson, Z., Hunt, J.E., Murindagomo, F. \& Macdonald, D.W. (2009b) Does the risk of encountering lions influence African herbivore behaviour at waterholes? Behavioral Ecology and Sociobiology, 63, 1483-1494.

Valeix, M., Loveridge, A.J., Davidson, Z., Madzikanda, H., Fritz, H. \& Macdonald, D.W. (2010) How key habitat features influence large terrestrial carnivore movements: waterholes and African lions in a semi-arid savanna of north-western Zimbabwe. Landscape Ecology, 25, $337-351$

Voigt, D.R. \& Earle, B.D. (1983) Avoidance of coyotes by red fox families. Journal of Wildlife Management, 47, 852-857.

Woodroffe, R., Thirgood, S. \& Rabinowitz, A. (2005) People and Wildlife, Conflict or Coexistence? Cambridge University Press, Cambridge. 
Table 1: Site selection at different distances from a cattle-post for resident lions in the Makgadikgadi ecosystem, Botswana

(a) Resident females in the migratory prey periods

\begin{tabular}{c|cccccccc} 
& $0-1 \mathrm{~km}$ & $1-2 \mathrm{~km}$ & $2-3 \mathrm{~km}$ & $3-4 \mathrm{~km}$ & $4-5 \mathrm{~km}$ & $5-6 \mathrm{~km}$ & $>6 \mathrm{~km}$ \\
\hline $0-1 \mathrm{~km}$ & 0 & - & --- & --- & --- & --- & -- \\
$1-2 \mathrm{~km}$ & + & 0 & --- & -- & -- & -- & - \\
$2-3 \mathrm{~km}$ & +++ & +++ & 0 & --- & --- & -- & - \\
$3-4 \mathrm{~km}$ & +++ & +++ & +++ & 0 & - & + & + \\
$4-5 \mathrm{~km}$ & +++ & +++ & +++ & + & 0 & + & + \\
$5-6 \mathrm{~km}$ & +++ & +++ & +++ & - & - & 0 & + \\
$>6 \mathrm{~m}$ & +++ & + & + & - & - & - & 0
\end{tabular}

(b) Resident females in the resident prey periods

\begin{tabular}{c|ccccccc} 
& $0-1 \mathrm{~km}$ & $1-2 \mathrm{~km}$ & $2-3 \mathrm{~km}$ & $3-4 \mathrm{~km}$ & $4-5 \mathrm{~km}$ & $5-6 \mathrm{~km}$ & $>6 \mathrm{~km}$ \\
\hline $0-1 \mathrm{~km}$ & 0 & -- & --- & -- & - & - & + \\
$1-2 \mathrm{~km}$ & +++ & 0 & - & - & + & + & +++ \\
$2-3 \mathrm{~km}$ & +++ & + & 0 & - & + & + & +++ \\
$3-4 \mathrm{~km}$ & +++ & + & + & 0 & + & + & +++ \\
$4-5 \mathrm{~km}$ & + & - & - & - & 0 & + & +++ \\
$5-6 \mathrm{~km}$ & + & - & - & - & - & 0 & +++ \\
$>6 \mathrm{~m}$ & - & --- & --- & -- & --- & --- & 0
\end{tabular}

(c) Resident males in the migratory prey periods

\begin{tabular}{c|ccccccc} 
& $0-1 \mathrm{~km}$ & $1-2 \mathrm{~km}$ & $2-3 \mathrm{~km}$ & $3-4 \mathrm{~km}$ & $4-5 \mathrm{~km}$ & $5-6 \mathrm{~km}$ & $>6 \mathrm{~km}$ \\
\hline $0-1 \mathrm{~km}$ & 0 & - & --- & -- & --- & --- & - \\
$1-2 \mathrm{~km}$ & + & 0 & --- & --- & -- & --- & - \\
$2-3 \mathrm{~km}$ & +++ & +++ & 0 & - & --- & -- & + \\
$3-4 \mathrm{~km}$ & +++ & +++ & + & 0 & --- & - & + \\
$4-5 \mathrm{~km}$ & +++ & +++ & +++ & +++ & 0 & + & +++ \\
$5-6 \mathrm{~km}$ & +++ & +++ & +++ & + & - & 0 & +++ \\
$>6 \mathrm{~m}$ & + & + & - & - & --- & --- & 0
\end{tabular}

(d) Resident males in the resident prey periods

\begin{tabular}{c|ccccccc} 
& $0-1 \mathrm{~km}$ & $1-2 \mathrm{~km}$ & $2-3 \mathrm{~km}$ & $3-4 \mathrm{~km}$ & $4-5 \mathrm{~km}$ & $5-6 \mathrm{~km}$ & $>6 \mathrm{~km}$ \\
\hline $0-1 \mathrm{~km}$ & 0 & - & --- & -- & -- & - & + \\
$1-2 \mathrm{~km}$ & + & 0 & - & - & - & - & +++ \\
$2-3 \mathrm{~km}$ & +++ & + & 0 & - & - & - & +++ \\
$3-4 \mathrm{~km}$ & +++ & + & + & 0 & - & + & +++ \\
$4-5 \mathrm{~km}$ & +++ & + & + & + & 0 & + & +++ \\
$5-6 \mathrm{~km}$ & + & + & + & - & - & 0 & +++ \\
$>6 \mathrm{~m}$ & - & -- & --- & -- & --- & -- & 0
\end{tabular}

The results presented are from compositional analyses. At the intersection of a row and a column, there is a "+" when the row class is more used than the column class, and "-" otherwise. When the difference is significant, the sign is tripled. 
Table 2: Summary statistics for linear mixed models of travel speed for resident lions in the Makgadikgadi ecosystem, Botswana. Lion identity and night identity were included as random effects, and autocorrelation was accounted for using a first-order autoregressive covariance structure for data from a same night.

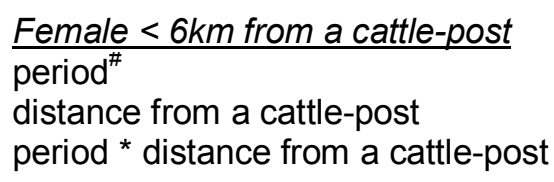

\begin{tabular}{rrr}
\hline$D F$ & $F$ & $P$ \\
\hline & & \\
1,4145 & 2.60 & 0.1072 \\
1,4145 & 57.74 & $<0.0001$ \\
1,4145 & 1.63 & 0.2017
\end{tabular}

Female inside national park period

$1,6616 \quad 5.78 \quad 0.0163$

Male $<6 \mathrm{~km}$ from a cattle-post period distance from a cattle-post

Male inside national park period

\# 'period' indicates period of prey abundance. 


\section{Figure legends:}

Figure 1: Example of monthly home ranges of lions in the Makgadikgadi ecosystem, Botswana: (a) one lioness following the migratory movements of wild herbivores (zebra and wildebeest), and (b) two lionesses that did not follow the migration but remained resident either in the West or in the East.

Figure 2: Prey preference of resident lions in the Makgadikgadi ecosystem, Botswana. The data used to calculate Jacobs' indices are from Loveridge et al. (2010).

Figure 3: Jacobs' indices for each distance-to-cattle-post category and each period of prey abundance for (a) resident female lions and (b) resident male lions in the Makgadikgadi ecosystem, Botswana. Positive values indicate preference, negative values indicate avoidance and null values indicate use in proportion of availability. Errors bars represent the $95 \%$ confidence interval.

Figure 4: Proportion of locations in which lions are within $1 \mathrm{~km}, 1-2 \mathrm{~km}$, and $2-3 \mathrm{~km}$ of a cattle-post by the time of the day for (a) resident female lions in the migratory prey period, (b) resident female lions in the resident prey period, (c) resident male lions in the migratory prey period, and (d) resident male lions in the resident prey period in the Makgadikgadi ecosystem, Botswana. The dashed line represents the proportion of equal distribution.

Figure 5: Relationship between average speed of lions and distance to a cattle-post for both sexes in the Makgadikgadi ecosystem, Botswana. The first row shows mean speed averaged over all months for resident females (a) and males (d); the second row takes the location 
inside/outside the protected area into account for resident females (b) and males (e); the third row takes seasonality into account for resident females (c) and males (f). The vertical dashed line represents the distance below which most livestock are located. 
Figure 1:
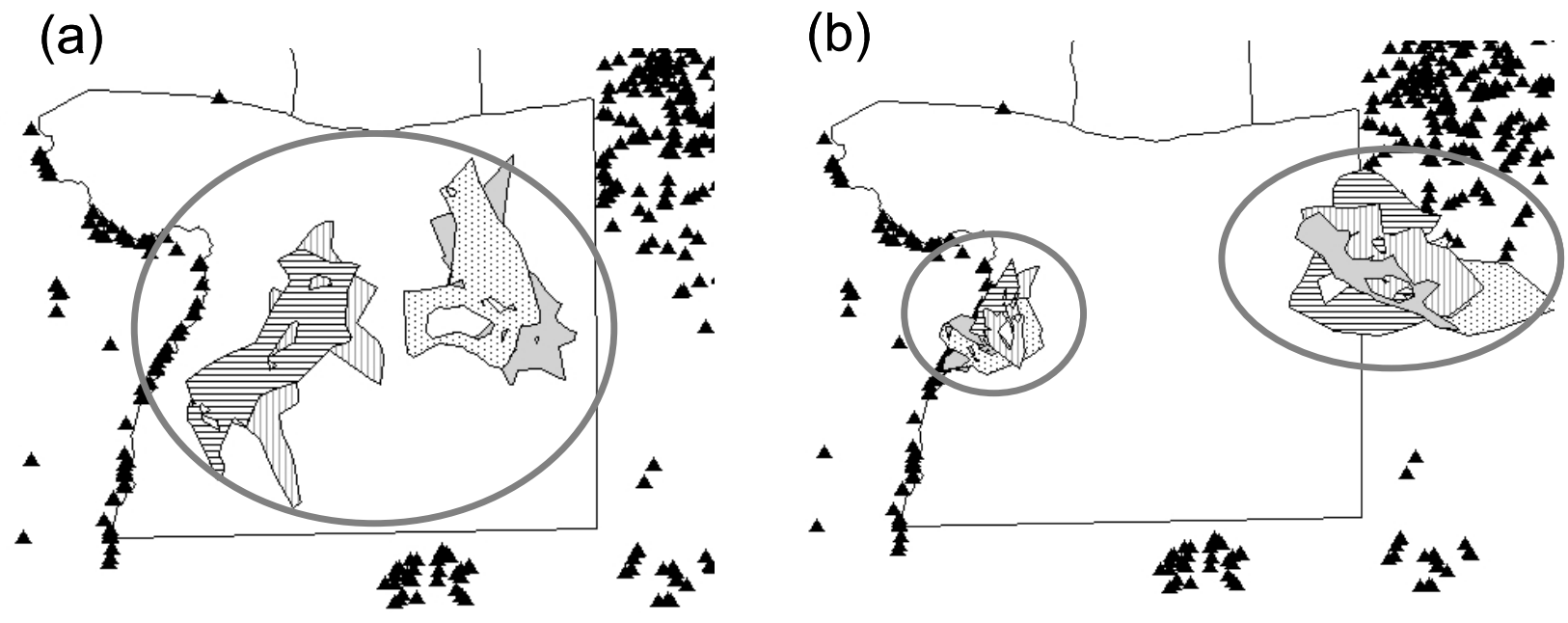

Dry season

home ranges

June 2002

July 2002
Wet season

home ranges

January 2002

February 2002
$\Delta$ cattle-post

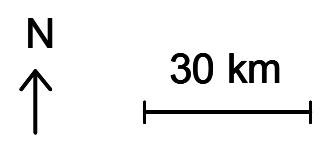

29 
Figure 2:

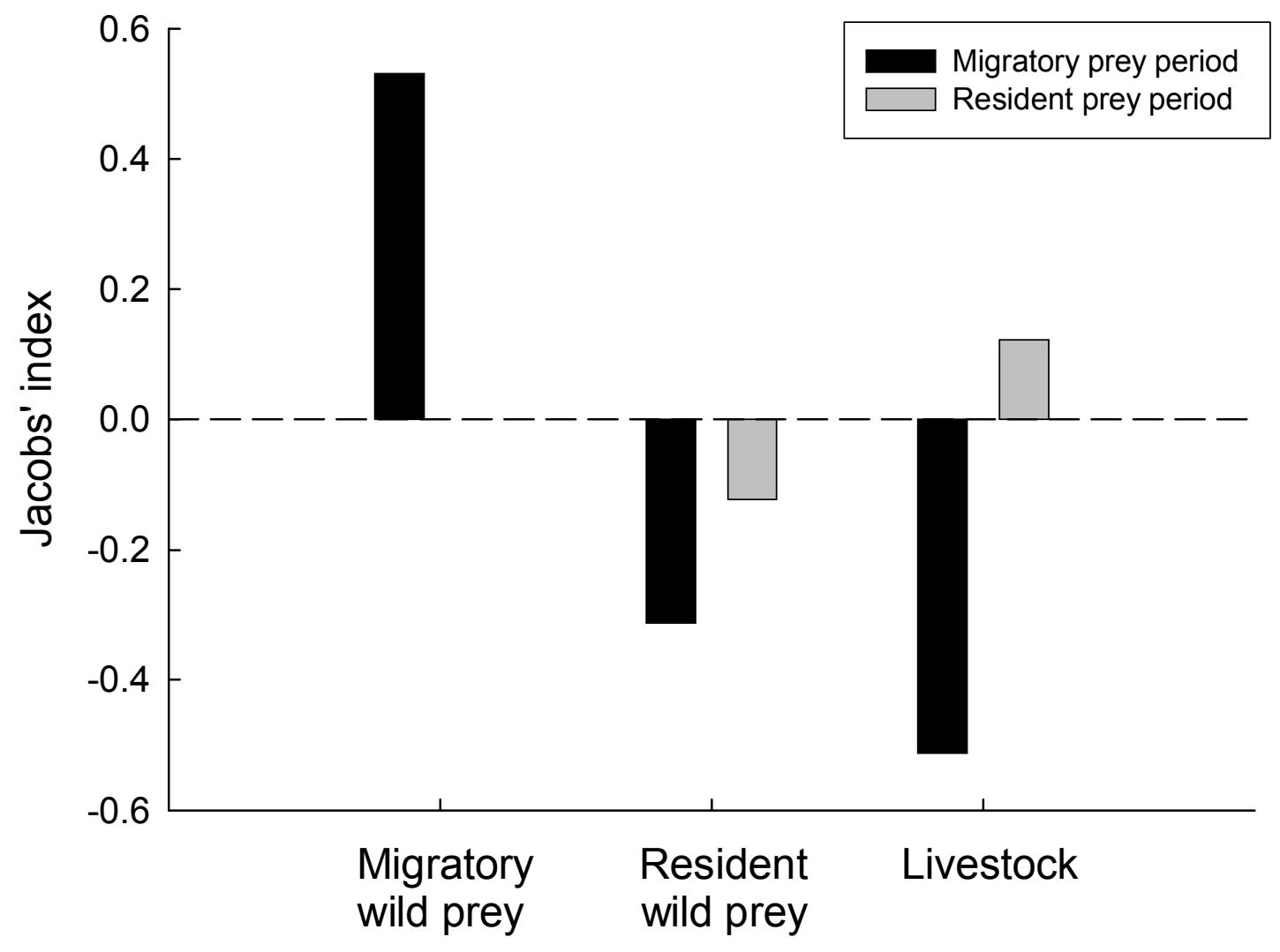


Figure 3 :
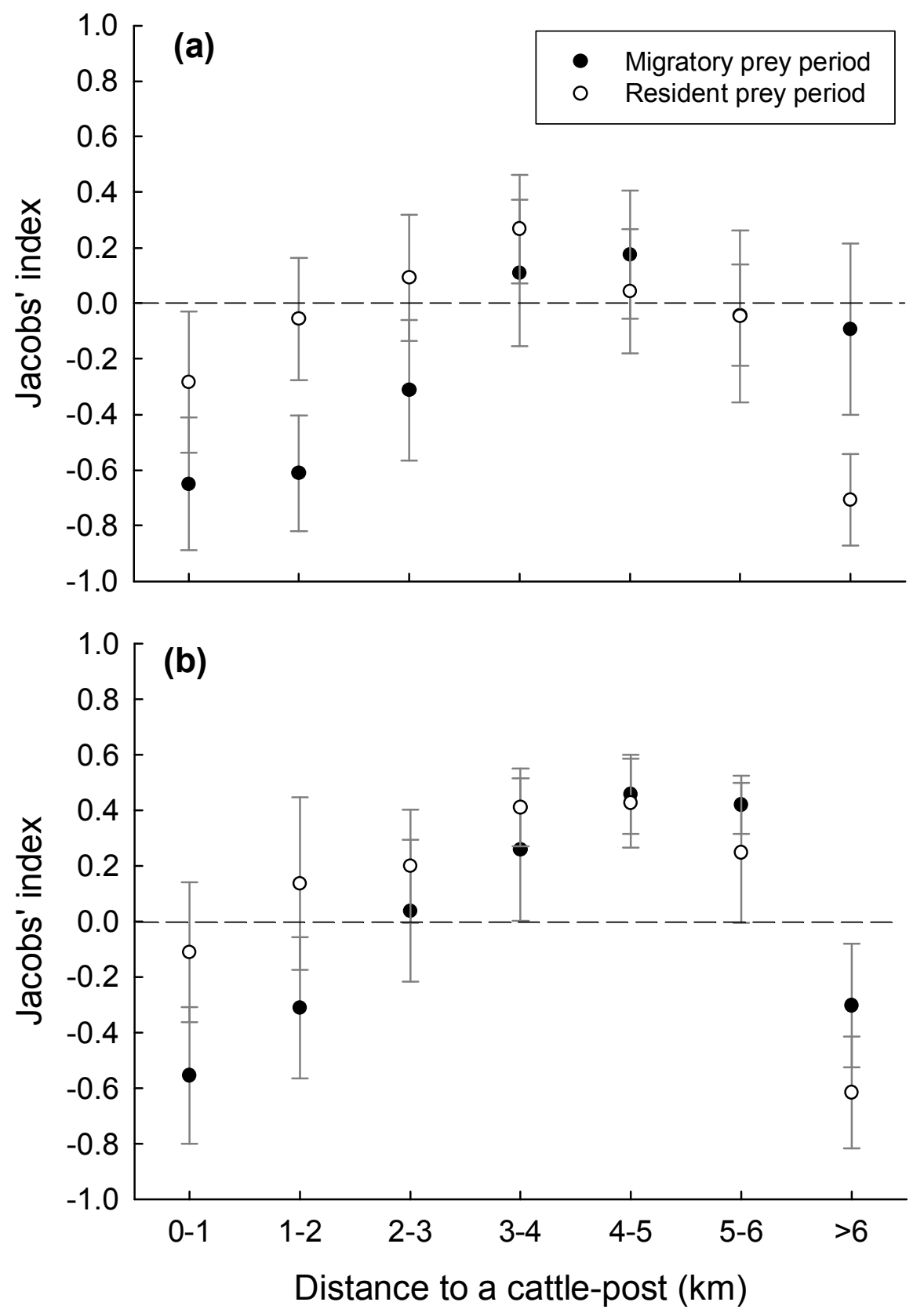
Figure 4:
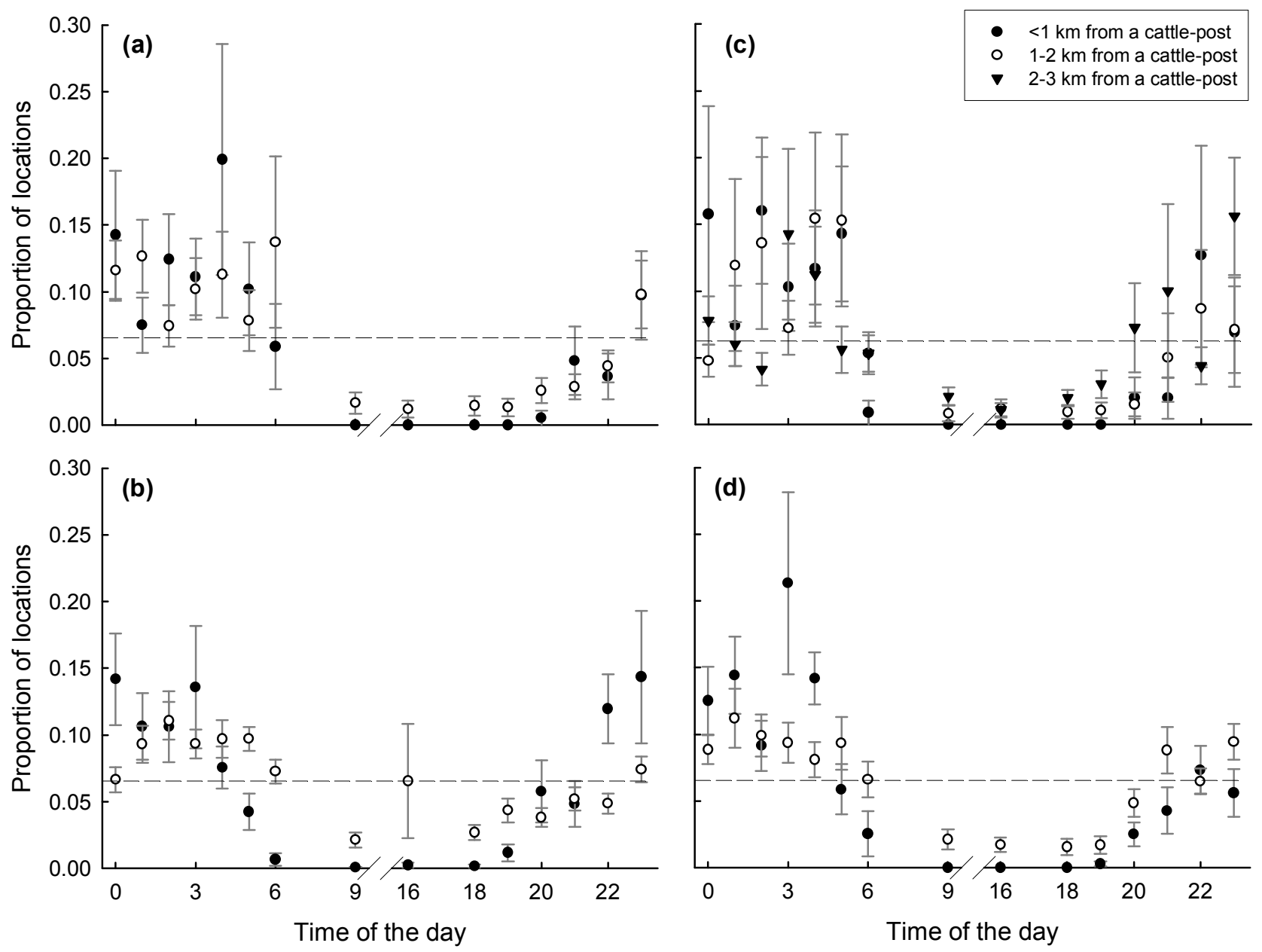
Figure 5:
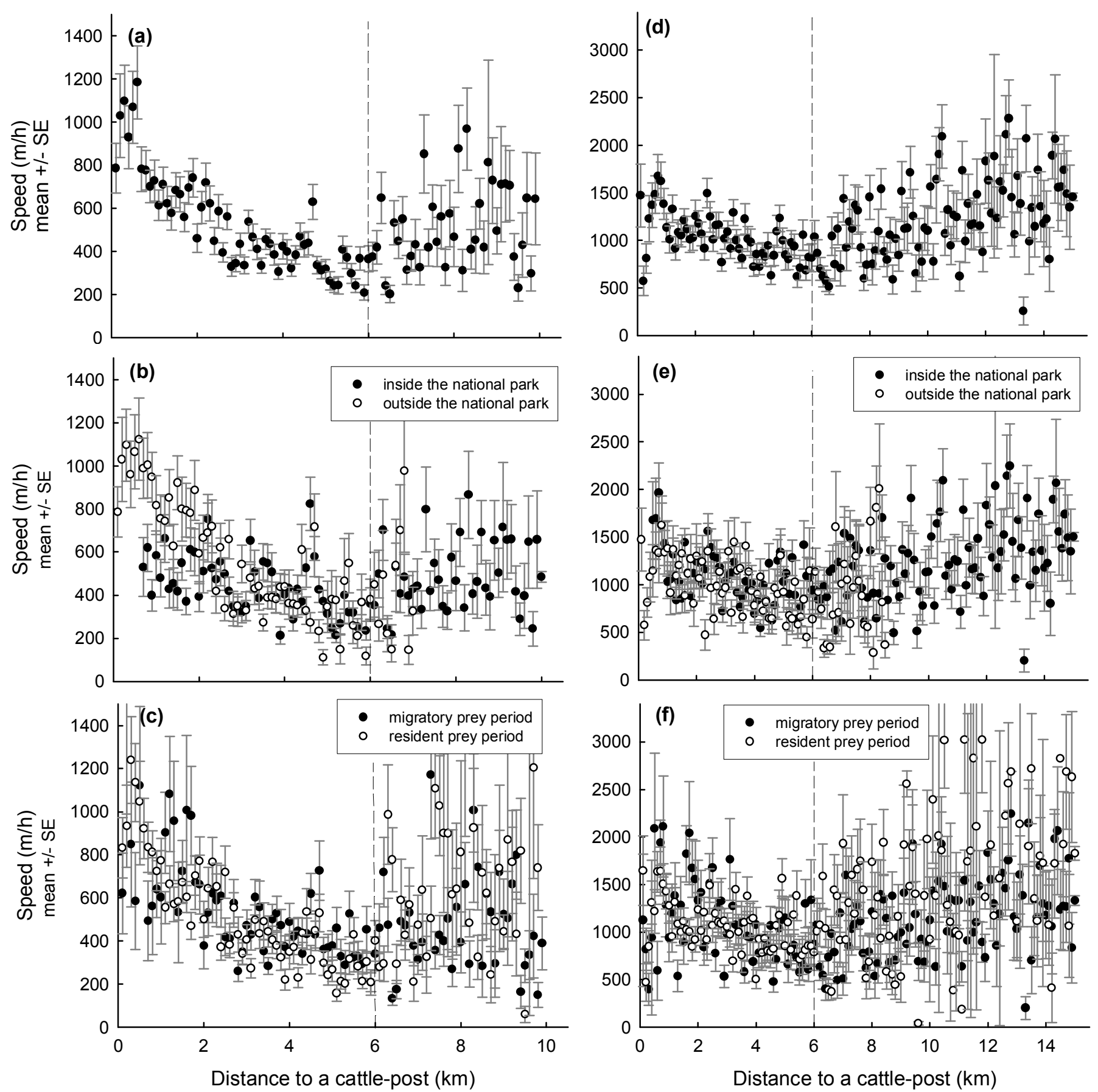